\title{
Space-Time Analysis of Migrations, Employment, and Housing as A Basis for Municipal Sustainable Urban Planning
}

\author{
Patricia Abelairas-Etxebarria *(D) and Inma Astorkiza \\ Department of Applied Economics V, University of the Basque Country (EHU/UPV), 48015 Leioa, Spain; \\ inma.astorkiza@ehu.es \\ * Correspondence: patricia.abelairas@ehu.es
}

Received: 25 February 2020; Accepted: 19 March 2020; Published: 21 March 2020

\begin{abstract}
A close relationship exists between population, the housing market and the level of employment at the local level. On the one hand, the housing market is influenced by local planning decisions and, on the other hand, that market is a significant factor in population and economic dynamization. Although there are studies on these variables, it is not common to include their spatial perspective by introducing Geographic Information System (GIS) tools in the analysis. The aim of this study is to analyse space-time associations among the variables migrations, housing prices, and employment prior to and during the economic crisis, in order to adapt sustainable land use policies to be used by land use planning authorities. Bivariate Exploratory Spatial Data Analysis (bivariate ESDA) has been used for this purpose. As our main results demonstrate, spatial positive autocorrelation was found between the variables employment in a village before the crisis and housing prices in neighbouring municipalities during it, indicating that people move to live in areas close to their workplace, but not necessarily to the same municipality. The analysis also shows spatial homogeneity of the variable housing prices, accompanied by temporal stability. The results indicate the need to implement sustainable control land use policies, not at the municipality level but at the county level.
\end{abstract}

Keywords: migration rate; housing; employment; sustainable urban planning

\section{Introduction}

Twenty years on, the land-use directives passed in 1997 by the Basque Autonomous Community (BAC) in Spain are coming under review in order to address new land-use challenges presented by the foreseeable post-crisis scenario [1]. The social, economic, and territorial framework for this review is marked by the current spatial distribution of the Basque population and its continuing tendency to concentrate in the metropolitan areas of the three provincial capitals (Bilbao, Donostia-San Sebastián, and Vitoria-Gasteiz), where $72 \%$ of the population already lives and works; and by the demographic trend projections published by the National Institute of Statistics [2] for the next 15 years, predicting, in line with the rest of Europe, a shrinking and significant ageing of the population.

In this context, it is worth investigating the causes of inter-municipal internal migration and its links with employment and housing, since these migratory movements and the resulting redistribution of the population affect not only the demand for public services and infrastructure but also municipal consumption of water and other natural resources and therefore have major public policy implications.

The causes of interurban migrations have been studied in the field of theoretical regional and urban economics. Roback [3] studied the role of wages and rents in allocating workers to locations with different amenities. These amenity differences produce wage and rent differentials that, in equilibrium, 
leave households and firms indifferent to changing locations. He also raised that regional wage differences can be explained largely by the local attributes. Mueser and Graves [4] presented a model of migration in which individuals and firms form rational expectations about future opportunities. Migration appears as a short-run response to disequilibrium in labour market. For this purpose, they used levels of migration as functions of variations in factors influencing migrant labour demand or "economic opportunity" and migrant labour supply or "residential amenities".

With regard to how planning policies affect the variables of this study, the influence of planning policies in the housing market should be highlighted. Thériault et al. [5] tested the efficiency of the French urban planning laws to control housing development in the coastal zone. They concluded that the role of the laws is not to restrict urbanization, but contribute to ease it, while controlling it. Also, they concluded that national laws need land planning to deploy locally, but that municipalities and stakeholders still prefer economic development over environmental conservation. In this line, Murphy [6] studies how planning for housing implies political conflict between the local government's and the central government's housing policies. He shows the dynamic of local and central government negotiations and the conflict arising from the development of Auckland's (New Zealand) spatial plan. He concluded that the legislation supporting housing accords alters central and local government power relations and that it represents a challenge to the existing planning system.

Furthermore, empirical analysis of linkages between migration, employment and housing prices can also be found throughout the literature, although it is remarkable that few studies have analysed, in particular, the relation between the price of housing and migrations. Dahl and Sorenson [7] studied the preferences of scientists and engineers for the places in which they choose to work and, they indicate sensitivity to differences in wages but, also, that they have stronger preferences for living close to family and friends. Buch et al. [8] investigated the determinants of the migration balance of German cities and they conclude that large cities, with their amenities, seem to be more attractive than small cities. Recently, Peng and Tsai [9] have studied the relation between migrations and the price of housing and concluded that migrations and house prices are cointegrated and that the influence of the price of housing on migrations is significantly positive in the long run, but it is not as significant as expected in the short run.

When analysing the studies on these variables, it is notable that the methodology varies according to objectives and data availability. Most authors base their studies on single-equation [10] or multi-equation structural econometric models, obtaining various results, some of which are counter-intuitive (areas with higher house prices attracting more migration). House prices and wages are treated as endogenous and simultaneous with migration at the regional level [4] and are jointly estimated using either a simultaneous equation framework [11,12] or its reduced form when aggregate regional/local data are available. In the latter case, wages and house prices are sometimes excluded, but even when they are included, the evidence for the influence of house prices on the migration decision is inconclusive (sometimes negative, positive or non-significant). Other authors, such as Saks [13] and Zabel [14], use Vector Auto-Regression (VAR) equation systems for their analyses.

Measurement error due to data aggregation or the failure to explicitly consider spatial interactions may have biased the estimates in previous studies and led to contradictory findings. Hence, there is a need for locally disaggregated data and for an approach in which spatial dependence and interactions between variables are taken into account. Along such lines, Jeanty et al. [15] developed a spatial general equilibrium model, starting with local level data (census tracts or "neighbourhoods" in Michigan), using two simultaneous equations and taking house prices and migration as dependent variables, but excluding the link with employment. Mitze et al. [16] used a spatial panel VAR approach to examine the interdependent dynamics of demographic structural changes and the job market but ignore housing market effects.

After reviewing the literature on the subject, we determined that a bivariate exploratory spatial data analysis (ESDA) was the most appropriate technique to study the relationship between the variables of interest. The reasons of that consideration were, on the one hand, that this method includes 
the spatial perspective, which has been shown to be important in this type of variables, and on the other hand, the absence of any of the a prioris and constraints imposed by different modelling techniques in this type of analysis, allows the data to speak for itself. Other recent studies, such as Guo et al. [17], Agovino et al. [18], Dou et al. [19], and Poudyala et al. [20], used this methodological approach to address issues relating to urban growth and related environmental problems.

The bivariate ESDA enables us to relate the value of a variable ' $x$ ' in a given locality with the value of another spatially lagged variable ' $y$ ' computed for neighbouring locations. The two variables were analysed both for the same time period and for a varying period. The space-time correlation of an observed variable over two different time periods, the years 2007 and 2014, was also obtained as a special case of standard bivariate ESDA. The reason for choosing those years in this work has to do with the recent economic crisis-more specifically, with the economic crisis in the Basque Autonomous Community.

The Basque Autonomous Community (BAC) suffered the impact of the international economic crisis that started in the United States in 2007. Below, Scheme 1 shows the Gross Domestic Product (GDP) and the unemployment rate obtained from the Basque Statistics Institute (EUSTAT).

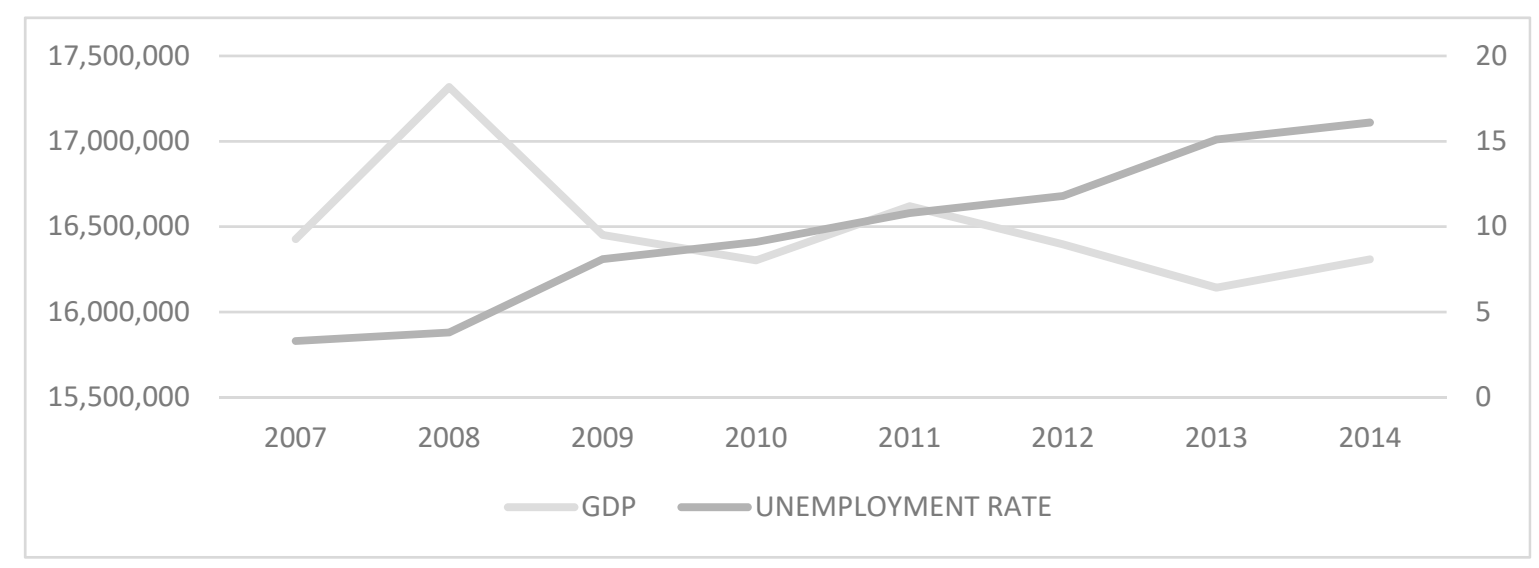

Scheme 1. GDP (thousands $€$ ) and unemployment rate (\%) in the Base Autonomous Community (BAC) from 2007 to 2014. Source: own elaboration extracted from Basque Statistics Institute (EUSTAT) data.

As can be seen in Graphic 1, the economic crisis began a little later in the BAC than in the United States. The trend changed in 2008, with a significant decline in GDP and, as expected, a significant increase in the unemployment rate. This makes the years 2007 and 2014 the years of interest in this study. The first one, 2007, as a reference of the situation that existed before the crisis began, and the second one, 2014, as the high point of the crisis in the context of the BAC. The possibility of studying every year from 2007 to 2014 was also considered. However, this option had to be ruled out due to the financial impossibility of accessing housing prices data of each year. Finally, we limit ourselves to the two years mentioned, which, as explained with the macroeconomic variables, was better collected the situation before and during the crisis.

The aim of this work is to carry out a statistical analysis of the space-time relationships between the above-mentioned variables in all Basque Autonomous Community municipalities before (2007) and after the onset (2014) of the last economic crisis, so as to detect any spatial dependencies and clusters and examine their spatial-temporal stability, all with a view to improving the rational and sustainable planning of land-uses.

For this purpose, as Figure 1 shows, after reviewing the literature, this paper shows a space-time bivariate exploratory data analysis, starting with the global space-time bivariate exploratory data analysis and finishing with the local space-time bivariate exploratory spatial data analysis. Once the analysis is done, the principal conclusions will be explained, and the bibliography used will be presented. 


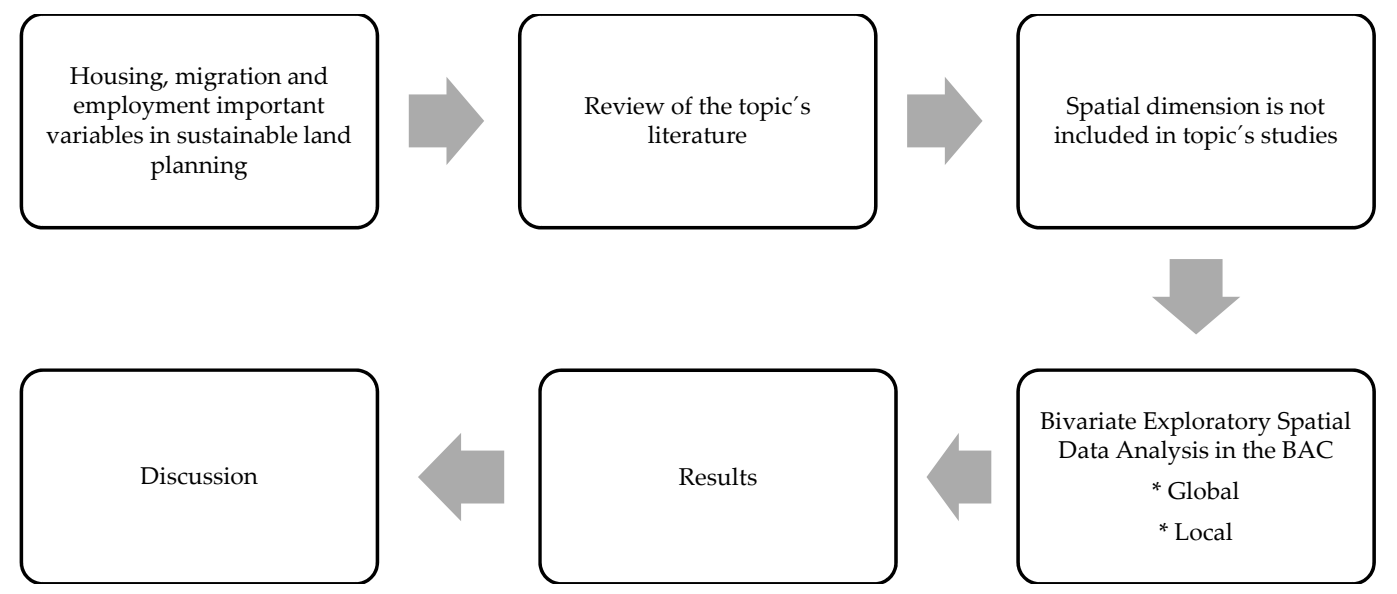

Figure 1. Flow chart of research. Source: own elaboration.

\section{Materials and Methods}

As it is shown in Figure 2, the Basque Autonomous Community is located in the North of Spain, and its principal villages are Bilbao, the capital of the province of Bizkaia; Donostia-San Sebastian, the capital of the province of Gipuzkoa; and Vitoria-Gasteiz, the capital of the province of Araba.
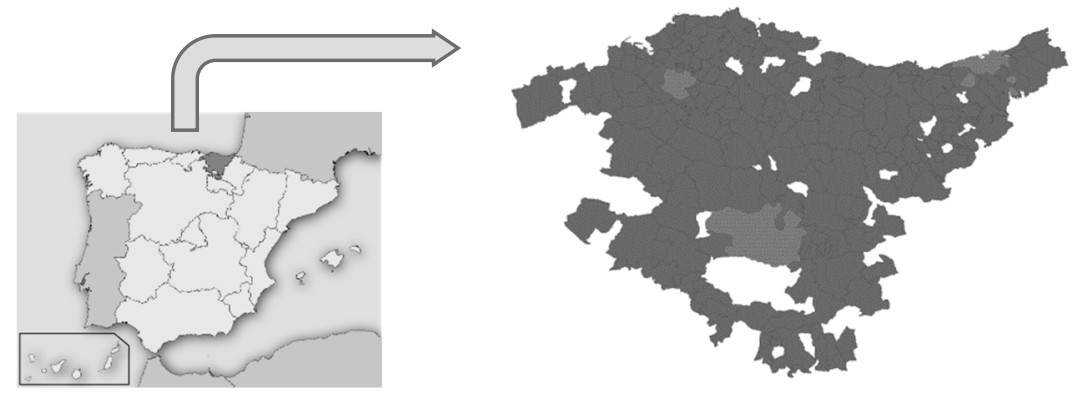

Figure 2. Basque Autonomous Community location and its capitals: Bilbao, Donostia-San Sebastian, and Vitoria-Gasteiz. Source: own elaboration.

Spatial data have been used to analyse the variables of interest for the 231 Basque municipalities for the years 2007 and 2014. The geo-referenced GIS database is based on municipal indicators published by the EUSTAT [21], from where migration and employment data have been collected. In addition, the data of house prices have been obtained from an archive created ad hoc by the real estate company Idealista.com. This company developed a database, as we request, with an average housing price per $\mathrm{m}^{2}$ for each municipality of the BAC. Specifically, they calculated the arithmetic average of all housing prices they had in each municipality in each year, 2007 and 2014. Depending on the municipality and on the year, the number of dwellings used to make this arithmetic average varies from 1, in some very small municipalities, to 107,000 in Bilbao, the biggest town in the BAC. Therefore, the sample used to obtain the average housing prices per $\mathrm{m}^{2}$ in each municipality of the BAC in 2007 and 2014 is 483,568 observations.

Table 1 describes the three variables and the weight spatial matrix used in this analysis. Concerning the variable collecting the Housing Price, the effect of inflation on the price per $\mathrm{m}^{2}$ of used housing has been corrected using the inflation rate published by the Spanish National Institute of Statistics (INE) and calculated in constant 2015 Euros. The variable collecting the Net Migration includes annual change-of-residence rate in each municipality, regardless of origin and destination, whether it is due to movement within the Basque Autonomous Community or from outside it, that is, from another of Spain's Autonomous Communities or from abroad. Regarding the variable collecting the Variation in Number of Jobs and the variable collecting the Net Migration, it should be noted that Net Migration and 
Variation in Number of Jobs is higher in the three provincial capitals (Bilbao, Donostia-San Sebastian, and Vitoria-Gasteiz) than in the rest of the Basque Autonomous Community, and these higher absolute values skew the results. This deficiency has been corrected by recalculating the variables per thousand of population.

Table 1. Description of variables used.

\begin{tabular}{|c|c|c|}
\hline Variable Acronym & Description & Source \\
\hline PV & $\begin{array}{c}\text { Price of used housing per } \mathrm{m}^{2} \text { calculated in constant } 2015 \text { Euros. } \\
\text { Its acronyms will be PV2007A in year } 2007 \text { and PV2014A in year 2014. It } \\
\text { will be called Housing Price during the analysis. }\end{array}$ & $\begin{array}{l}\text { Idealista.com and } \\
\text { INE }\end{array}$ \\
\hline $\mathrm{SM} 000 \mathrm{H}$ & $\begin{array}{l}\text { Annual change-of-residence rate (difference between entries and exits) } \\
\text { in each municipality. It can take both positive (entry of new residents) } \\
\text { and negative (exit of residents) values. } \\
\text { Its acronyms will be SM000H07 in year } 2007 \text { and SM000H14 in year } \\
\text { 2014. It will be called Net Migration during the analysis. }\end{array}$ & EUSTAT \\
\hline $\mathrm{DE} 000 \mathrm{H}$ & $\begin{array}{l}\text { Annual differences in the number of jobs in firms of all sectors located } \\
\text { in the municipality, per thousand inhabitants. It can take positive } \\
\text { values (job growth) or negative values (job losses). } \\
\text { Its acronyms will be DE000H07 in year } 2007 \text { and DE000H14 in year } 2014 . \\
\text { It will be called Variation in Number of Jobs during the analysis. }\end{array}$ & EUSTAT \\
\hline WCONTIG & $\begin{array}{l}\text { First-order row-standardized contiguity-based spatial weights matrix. } \\
\text { Neighbouring municipalities are those that are physically contiguous } \\
\text { according to the queen contiguity criterion (municipalities sharing any } \\
\text { of their four sides or four vertices with other municipalities). }\end{array}$ & Own calculation \\
\hline
\end{tabular}

Source: own elaboration.

\section{Results}

\subsection{Global Space-Time Bivariate Exploratory Data Analysis}

Analysis of associations between the three variables of interest (Housing Price, Net Migration and Variation in Number of Jobs) at the local level, before and after the onset of the crisis, requires consideration of the space-time factor. To this end, the Bivariate Exploratory Spatial Data Analysis starts by analysing global spatial correlation before moving on to analyse local clusters.

The specification for the global spatial autocorrelation analysis is in line with the criteria proposed by Mitze et al. [16] based on Lopez et al. [22]. Such that, for a variable ' $y$ ', Moran's I is defined as $M I_{y}=\frac{N}{S_{0}} \frac{\sum_{i=1}^{N} \sum_{j=1}^{N} w_{i j}^{(y)} z_{i} z_{j}}{\sum_{i=1}^{N} z_{i}^{2}} \forall i \neq j$, where $N$ is the total number of municipalities, $z_{i}$ and $z_{j}$ are normalized values of ' $y$ ' in municipalities $i$ and $j, w_{i j}$ is the typical element of the spatial weights matrix $\mathrm{W}$ (WCONTIG), and $S_{0}$ is a scaling constant. For longitudinal data, a straightforward Space-Time extension of Moran's I (STMI) can be defined as: $S T M I_{y}=\mathrm{I}_{\mathrm{T}} \otimes M I_{y}$, where $\mathrm{I}_{\mathrm{T}}$ is an identity matrix of dimension $\mathrm{T}$ (time).

Table 2 collects the results from this statistic, which is the most suitable for studying the global spatial autocorrelation for the spatial-temporal data this paper analyses. As it can be seen, the Housing Price variable shows space-time autocorrelation, but Net Migration and Variation in Number of Jobs do not. That is, Housing Price in 2007 is spatially correlated with Housing Price in 2014, but this does not happen with the variables Net Migration and Variation in Number of Jobs. It could be said that this autocorrelation indicates a stable trend in Housing Price in the pre-crisis and crisis periods. 
Table 2. Space-time Moran's I test for spatial autocorrelation.

\begin{tabular}{ccccc}
\hline Variable & STMI & z-Statistic & $\rho$-Val. & Inference for STMI \\
\hline Housing Price & 0.4930 & 10.9168 & 0.001 & $\begin{array}{c}\text { Reject } \mathrm{H}_{0} \\
\text { Presence of space-time } \\
\text { autocorrelation }\end{array}$ \\
\hline Net Migration & -0.0111 & -0.2989 & 0.384 & $\begin{array}{c}\text { Accept } \mathrm{H}_{0} \\
\text { Absence of space-time } \\
\text { autocorrelation }\end{array}$ \\
\hline $\begin{array}{c}\text { Variation in Number } \\
\text { of Jobs }\end{array}$ & -0.0542 & -1.4804 & 0.066 & $\begin{array}{c}\text { Accept } \mathrm{H}_{0} \\
\text { Absence of space-time } \\
\text { autocorrelation }\end{array}$ \\
\hline
\end{tabular}

Source: own elaboration.

Following with the analysis of the presence of autocorrelation between the Housing Price variable in 2007 and the Housing Price variable 2014, it is remarkable that this autocorrelation is positive- that is, neighbouring municipalities have similar prices in the year 2007 and in the year 2014.

Figure 3 shows that positive global spatial correlation, where most of the observations are located in the first and third quadrants, showing the existence of this type of spatial autocorrelation. If a village has high Housing Price in 2007, its neighbours will also present high prices in 2014. Moreover, if a municipality has low Housing Price in 2007, its neighbours will also present low prices. Linking with that bivariate autocorrelation between Housing Price variable in 2007 and Housing Price variable in 2014, the univariate spatial autocorrelation for this variable in the year 2007 and in the year 2014 has been analyzed also. The purpose of this was to know if the temporal stability of the Housing Price variable (similar prices in neighbouring towns before and during the crisis) is accompanied with spatial homogeneity (similar Housing Price in neighbouring towns in the same year).

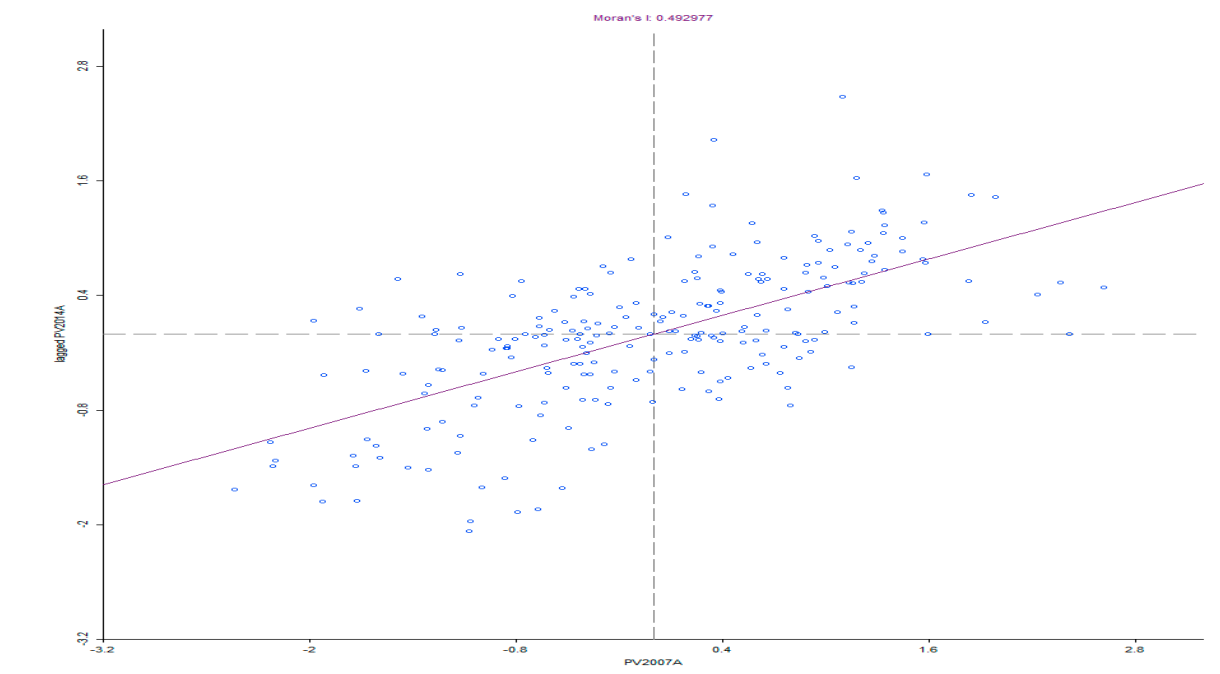

Inference for Space-time Moran's I: I = 0.4930; Mean =-0.0043; SD = 0.0457; Z(I) = 10.9168; P [0 $\leq$

$\mathrm{N}(0,1) \leq 10.9168]=0.5$; Pseudo $p$-value $=0.001$; Reject $\mathrm{H}_{0}$ : Global spatial autocorrelation

Figure 3. Space-time Moran's I for Housing Price in 2007 and in 2014. Source: own elaboration.

As it can be seen in Figure 4, which collects univariate Moran's I for Housing Price in 2007 and 2014, that most of the observations are located in the first and third quadrants in both 2007 and 2014, showing the existence of positive spatial autocorrelation before and during the crisis-that is, most municipalities have similar prices to those of adjacent municipalities in 2007 and in 2014. In addition, the positive and significant value of Moran's I confirms the existence of global positive spatial autocorrelation. It is confirmed that Housing Price variable presents temporal stability accompanied 
with spatial homogeneity. Housing Price in neighbouring municipalities were similar before starting the crisis in 2007 and are similar in the municipalities and their neighbouring towns in the year 2014.

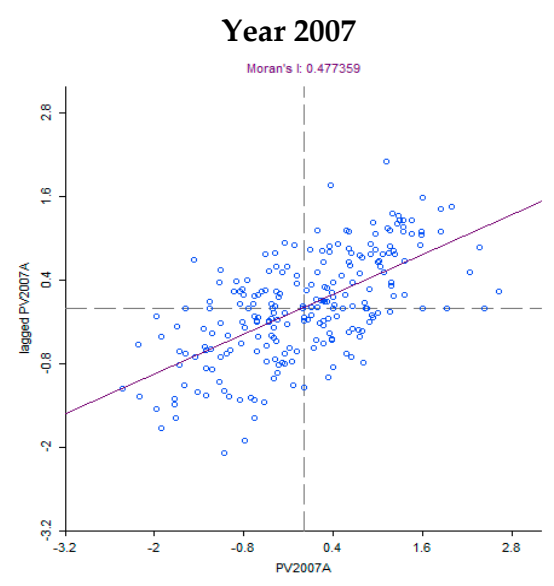

Inference for Moran's I: I = 0.4774; Mean $=-0.0043$; $\mathrm{SD}=0.0487 ; \mathrm{Z}(\mathrm{I})=9.8974 ; \mathrm{P}[0 \leq \mathrm{N}(0,1) \leq 9.8974]=$ $0.50 ;$ Pseudo $p$-value $=0.001$

Reject $\mathrm{H}_{0}$ : Global spatial autocorrelation

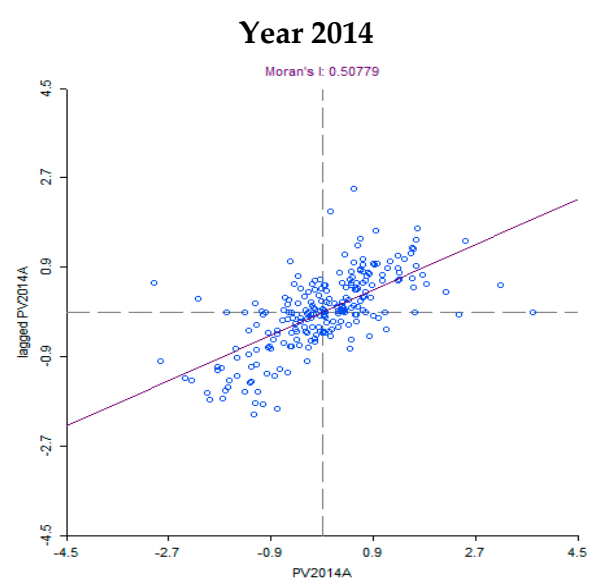

Inference for Moran's I: I $=0.5078$ Mean $=-0.0043 ; \mathrm{SD}=$ $0.0487 ; \mathrm{Z}(\mathrm{I})=10.5226 ; \mathrm{P}[0 \leq \mathrm{N}(0,1) \leq 10.5226]=0.50$;

Pseudo $p$-value $=0.001$, Reject $\mathrm{H}_{0}$ : Global spatial autocorrelation

Figure 4. Univariate Moran's I for Housing Price in 2007 and in 2014. Source: own elaboration.

Following with the global bivariate analysis, all the rest of relations between the three variables in the two years of study have been studied. Nevertheless, just one more (besides the Housing Price in 2007 with the Housing Price in 2014 explained above) presents spatial autocorrelation: the variable Housing Price in 2007 (PV2007A) with the variable Net Migration in 2007 (SM000H07). All the remaining relationships between the three variables present non-significant global spatial correlation.

According to Figure 5, Housing Price and Net Migration show negative global bivariate spatial correlation, before the onset of the crisis, that is, in 2007. In other words, if the Housing Price in a given municipality was high, then the Net Migration of its neighbours was low, and, conversely, if the Housing Price in the municipality is low, the Net Migration of its neighbours was high. Linking with that, the similarity of house prices between the villages and their neighbours in 2007 (the positive global univariate spatial autocorrelation of Housing Price in 2007 showed in Figure 4) has its origins in these high prices, which are the same for the whole area (in their neighbouring municipalities). This fact discourages immigration to any municipality in the zone. The opposite reasoning can be applied when house prices are low. 


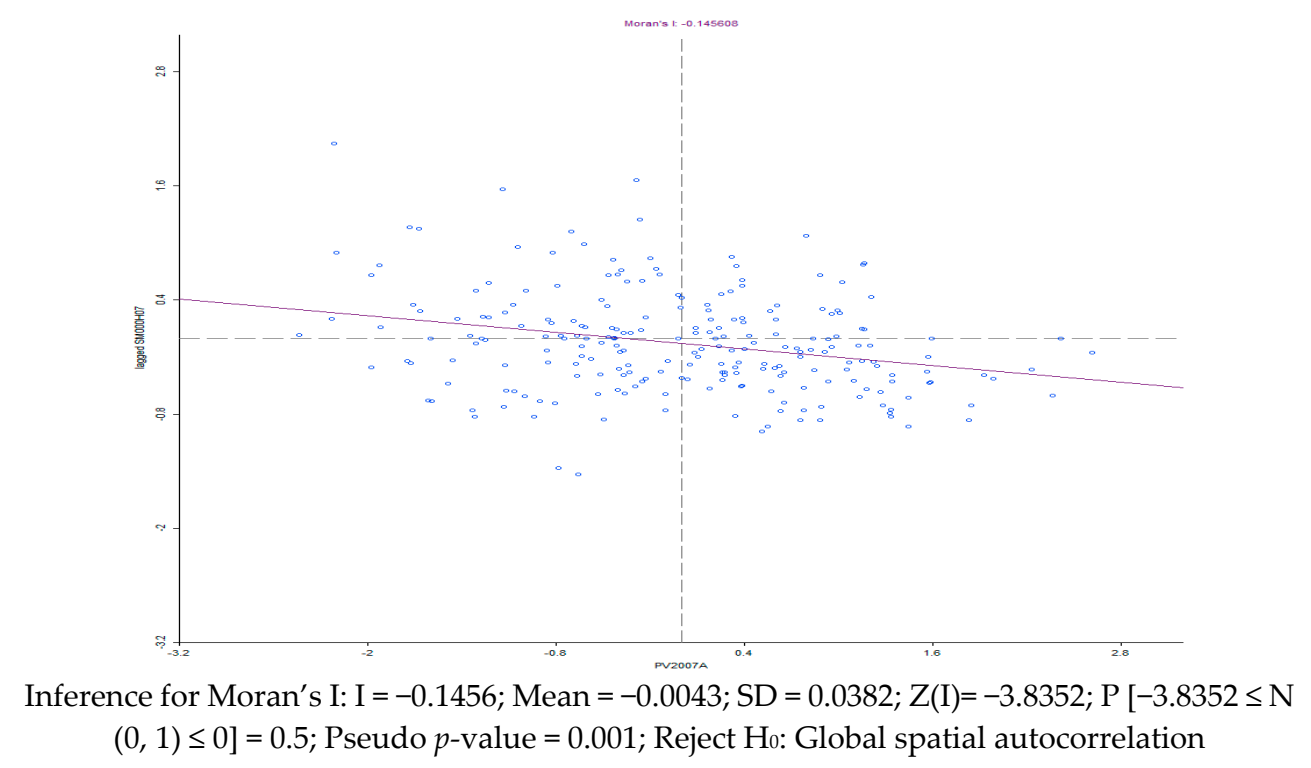

Figure 5. Bivariate Moran's I for Housing Price and Net Migration in 2007. Source: own elaboration.

\subsection{Local Space-Time Bivariate Exploratory Spatial Data Analysis}

Once the Global Space-time Bivariate Exploratory Data Analysis is done, the Local Space-Time Bivariate Exploratory Data Analysis will be presented, with the principal aim of analysing local clusters of the three variables of interest.

The Bivariate Local Indicators of Spatial Associations (BLISAs) relevant clusters maps are presented in Table 3. The capitals of the three provinces-Bilbao, Donostia-San Sebastian, and Vitoria-Gasteiz-are marked in the maps. However, in some maps, they are superimposed by a cluster.

The rest of the BLISAs maps, showing the rest of the relations between the variables of interest in the two years, are not included because they identify just a few local clusters and, in addition to this, they are scattered and varied, so that conclusions cannot be drawn from them.

Map 2 collects the BLISAs cluster map of the variable Housing Price between the years 2007 and 2014. It shows the local clusters between the Housing Price before the crisis (2007) and during it (2014), and it identifies 54 locations with significant local dependence. Practically, all the clusters present positive correlation-that is, municipalities with high pre-crisis prices are surrounded by locations with high prices in 2014, and the same happens with low prices. This fact is in line with the global spatial-temporal Moran's I (STMI) test results shown previously in Table 2, which indicated space-time autocorrelation for the Housing Price variable in a global context. As expected, Bilbao and some coast municipalities near it are some of the clusters identified presenting a positive spatial correlation with high prices in 2007 surrounding by high prices in 2014. Also, some high-high clusters are identified surrounding Donostia-San Sebastian, but not in the city itself, and some low-low clusters are found surrounding Vitoria-Gasteiz but, again, not in the capital of the province.

Map 3 collects Housing Price and Net Migration linkages between years 2007 and 2014 and identifies just 26 locations with significant local spatial dependence. However, Map 4 shows the inverse relation-how Net Migration in 2007 in a municipality is related to Housing Price in 2014 in its neighbours-and finds 52 clusters. These results indicate stronger spatial autocorrelation in one direction than in the other. 
Table 3. Bivariate Local Indicators of Spatial Associations (BLISAs) cluster maps.

Map 2. Housing price in 2007 and housing price in 2014.

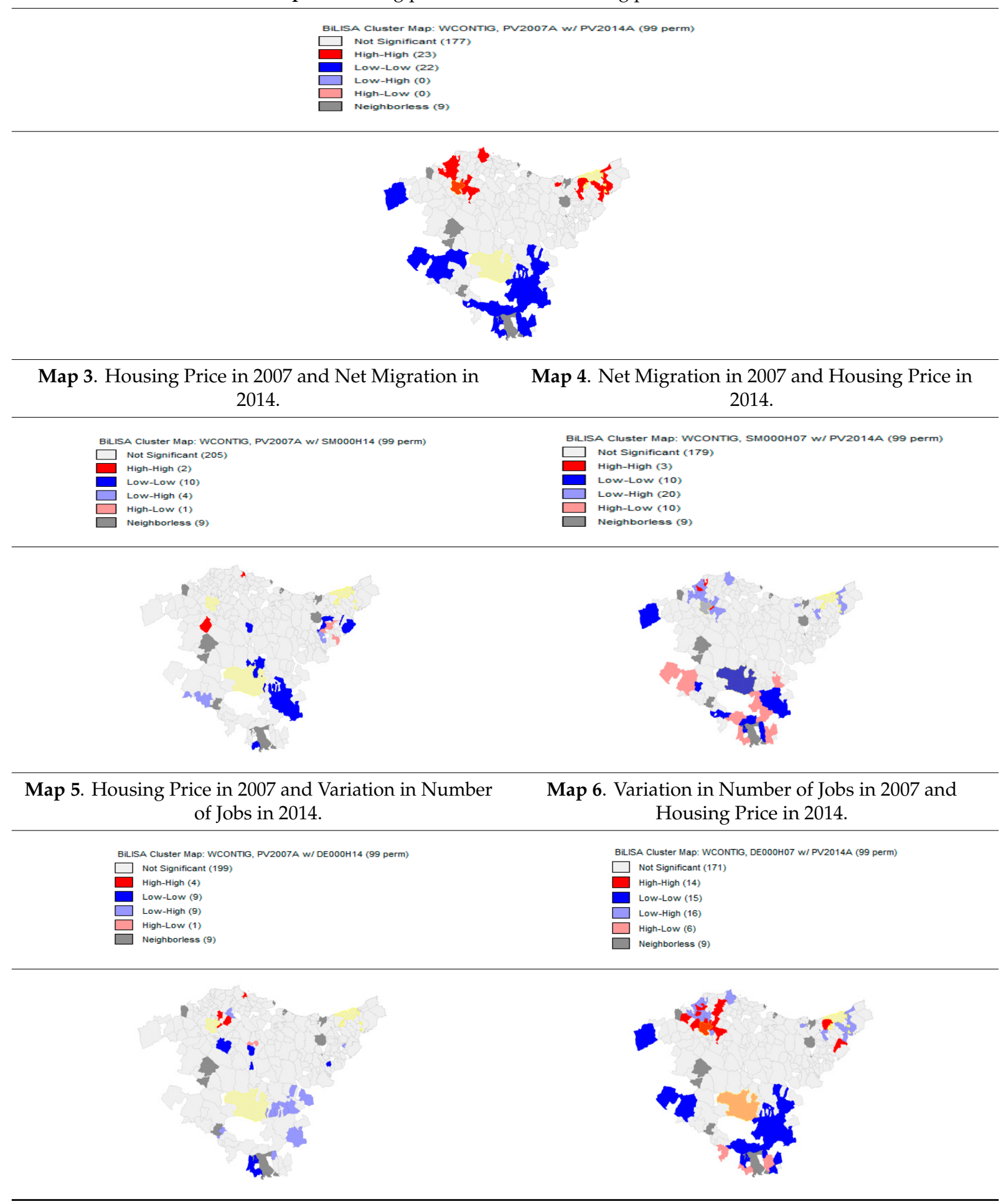

Source: own elaboration.

Most of the clusters identified by Map 4 show negative spatial autocorrelation, as the global analysis has showed previously between Net Migration and Housing Price in 2007. That correlation shows that municipalities with high migration in 2007 are surrounding by villages with high prices in 2014 and that municipalities with low migration before the crisis-that is, losing citizens before the crisis, are surrounding by municipalities with high prices during the crisis. Most of these last clusters 
are located around Bilbao, where prices for housing are in general high because of the proximity to the capital.

Maps 5 and 6, collecting the relationship of Housing Price and Variation in Number of Jobs between 2007 and 2014, reveals a similar phenomenon to the one described above. Fewer clusters (32 clusters in Map 5) emerge when relating Housing Prices in 2007 in a location with the Variation in Number of Jobs in 2014 in neighbouring towns, than if the variables are reversed (60 clusters shown in Map 6). The spatial autocorrelation of the variable Variation in Number of Jobs in 2007 in a municipality on Housing Price in 2014 in the neighbouring municipalities is greater than the spatial autocorrelation of Housing Price in 2007 in a village with the Variation in Number of Jobs in 2014 in the neighbouring towns. Also, it is outstanding, as Map 6 shows, that Bilbao and municipalities near it present high-high clusters and that Vitoria-Gasteiz shows a high-high cluster, but some municipalities near it show low-low clusters.

The bivariate spatial-temporal analysis was extended to a multivariate framework by estimating three econometric models, each using one of the three variables of interest as the dependent variable and the other two as the independent variables. The results for the model with Housing Price as the dependent variable performed best, since the coefficients from the other two models have not sufficient significance to be taken into account.

First, an estimation for Ordinary Least Squares (OLS) has been made for the two years, as shown in Table 4. In addition, the diagnosis of the presence of spatial autocorrelation and the Lagrange Multipliers have been obtained for, in case of existing said spatial relationship, specify the type of this correlation.

Table 4. Ordinary Least Squares (OLS) and Spatial Error estimation in 2007 and 2014.

\begin{tabular}{|c|c|c|c|c|c|c|c|c|c|}
\hline \multicolumn{5}{|c|}{2007} & \multicolumn{5}{|c|}{2014} \\
\hline \multicolumn{5}{|c|}{ OLS ESTIMATION } & \multicolumn{5}{|c|}{ OLS ESTIMATION } \\
\hline \multicolumn{3}{|c|}{ Dependent Variable: PV2007A } & \multicolumn{2}{|c|}{ R-square: 0.038963} & \multicolumn{3}{|c|}{ Dependent Variable: PV2014A } & \multicolumn{2}{|c|}{ R-square: 0.021575} \\
\hline Variable & Coefficient & Std. Error & t-Statistic & Probability & Variable & Coefficient & Std.Error & t-Statistic & Probability \\
\hline CONSTANT & 2907.062 & 94.70631 & 30.69555 & 0.00000 & CONSTANT & 1780.501 & 39.6798 & 44.87171 & 0.00000 \\
\hline SM000H07 & -9.059709 & 3.16018 & -2.866827 & 0.00453 & DE000H14 & 1.525538 & 1.13397 & 1.345307 & 0.17986 \\
\hline DE000H07 & 2.264397 & 2.096728 & 1.079967 & 0.28130 & SM000H14 & 3.676852 & 2.104673 & 1.746995 & 0.08199 \\
\hline \multicolumn{5}{|c|}{ DIAGNOSTICS FOR SPATIAL DEPENDENCE } & \multicolumn{5}{|c|}{ DIAGNOSTICS FOR SPATIAL DEPENDENCE } \\
\hline \multicolumn{2}{|c|}{ TEST } & $\mathrm{MI} / \mathrm{DF}$ & VALUE & PROB & \multicolumn{2}{|c|}{ TEST } & $\mathrm{MI} / \mathrm{DF}$ & VALUE & PROB \\
\hline \multicolumn{2}{|c|}{ Moran's I (error) } & 0.4456 & 9.0510 & 0.00000 & \multicolumn{2}{|c|}{ Moran's I (error) } & 0.4922 & 10.0148 & 0.00000 \\
\hline \multicolumn{2}{|c|}{ Lagrange Multiplier (lag) } & 1 & 60.0863 & 0.00000 & \multicolumn{2}{|c|}{ Lagrange Multiplier (lag) } & 1 & 58.3579 & 0.00000 \\
\hline \multicolumn{2}{|c|}{ Robust LM (lag) } & 1 & 0.5478 & 0.45923 & \multicolumn{2}{|c|}{ Robust LM (lag) } & 1 & 0.0519 & 0.81971 \\
\hline \multicolumn{2}{|c|}{$\begin{array}{l}\text { Lagrange Multiplier } \\
\text { (error) }\end{array}$} & 1 & 78.8824 & 0.00000 & \multicolumn{2}{|c|}{$\begin{array}{l}\text { Lagrange Multiplier } \\
\text { (error) }\end{array}$} & 1 & 96.2340 & 0.00000 \\
\hline \multicolumn{2}{|c|}{ Robust LM (error) } & 1 & 19.3438 & 0.00001 & \multicolumn{2}{|c|}{ Robust LM (error) } & 1 & 37.9281 & 0.00000 \\
\hline \multicolumn{2}{|c|}{$\begin{array}{l}\text { Lagrange Multiplier } \\
\text { (SARMA) } 2\end{array}$} & 2 & 79.4302 & 0.00000 & \multicolumn{2}{|c|}{$\begin{array}{l}\text { Lagrange Multiplier } \\
\text { (SARMA) } 2\end{array}$} & 2 & 96.2860 & 0.00000 \\
\hline
\end{tabular}

\begin{tabular}{ccccccccccc}
\hline \multicolumn{4}{c}{ SPATIAL ERROR ESTIMATION } & \multicolumn{5}{c}{ SPATIAL ERROR ESTIMATION } \\
\hline \multicolumn{2}{c}{ Dependent Variable: PV2007A } & R-square: 0.375144 & \multicolumn{2}{c}{ Dependent Variable: PV2014A } & \multicolumn{2}{c}{ R-square: 0.412882 } \\
\hline Variable & Coefficient & Std.Error & z-value & Probability & Variable & Coefficient & Std.Error & z-value & Probability \\
\hline CONSTANT & 2858.553 & 134.5117 & 21.25134 & 0.00000 & CONSTANT & 1791.732 & 70.84953 & 25.28925 & 0.00000 \\
\hline DE000H07 & 1.10457 & 1.605804 & 0.6878611 & 0.49154 & SM000H14 & 1791.732 & 70.84953 & 25.28925 & 0.00000 \\
\hline SM000H07 & -4.844724 & 2.37802 & -2.037293 & 0.04162 & DE000H14 & -0.0440175 & 0.877463 & -0.05016454 & 0.9599 \\
\hline LAMBDA & 0.5807406 & 0.05542229 & 10.47847 & 0.00000 & LAMBDA & 0.6160491 & 0.05221576 & 11.79814 & 0.00000 \\
\hline & & \multicolumn{3}{c}{ Source: own elaboration. } & & &
\end{tabular}

The first OLS estimations in the two years are not remarkable but, as we have seen throughout the analysis, the existence of spatial autocorrelation is verified with the Moran's I statistic both in 2007 and in 2014. Observing the Lagrange multipliers, it can be said that there is residual spatial autocorrelation in both cases, which indicates the need to estimate the spatial error models, which are shown in Table 4. 
According to the $\mathrm{R}^{2}$ of the spatial error model in 2007, the model explains $37.5 \%$ of the variation in the Housing Price. As ESDA results have indicated, the Net Migration variable appears as a significant variable with a negative sign and Variation in Number of Jobs variable is not significant. On the other hand, the spatial error model in 2014 explains $41.3 \%$ of the variability in the Housing Price. Again, the Net Migration variable again appears as significant, but in this case with a positive sign. The variable that collects the Variation in Number of Jobs is not significant, as it happened in the year 2007.

\section{Discussion}

This analysis and its results provide a better understanding of the interrelationships among migrations, housing and employment and may, ultimately, help to achieve more rational and sustainable land use planning.

Firstly, and contrary to what was expected, no relevant relationship between the migration and employment variables has been found, neither in ESDA analysis nor in econometric analysis. Secondly, a relationship has been found between employment and housing prices variables at the local level. BLISA clusters maps identify some locations with significant local positive spatial dependence. Municipalities that show a positive value of employment before the crisis, are surrounding by towns with high housing prices in 2014, perhaps because of the high housing demand caused by people seeking to fill those new jobs created before in 2007 and seeking to settle in that area with high economic activity. This extreme would support the idea that people move to live in areas close to their workplace, but not necessarily to the same municipality-in other words, job growth in a location tends to be accompanied by a dynamic real estate sector and high house prices in the surrounding towns.

In addition, a temporary asymmetry has been found in the relationship between housing prices and migration variables, since the relation between migrations before the crisis and the housing prices after it is stronger than the relation between housing price before the crisis and the migrations after it. This same phenomenon happens between the employment and housing price variables, with the relationship between employment before the crisis and the price of housing during the crisis being stronger than vice versa. It could be said that the deep crisis experienced in recent years and all its consequences has modified the relationships between these variables.

Finally, it has been confirmed that housing prices present temporal stability and spatial homogeneity. Both before and during the crisis, the housing prices in the municipalities of the $\mathrm{BAC}$ and in the nearby municipalities are similar. It is remarkable that the deep economic crisis has not modified the patterns of housing price. Areas with high housing prices before the crisis continue being areas with high housing prices during it. If this point is linked with the negative spatial relation found between housing prices and migration, both in bivariate and in multivariate analysis, it could be said that, high housing prices discourage immigration to the whole area and not only to the municipality itself but also to its neighbours, while low housing prices areas tend to attract buyers from outside.

During the long build-up to the peak, housing markets in developed countries moved in a remarkably synchronized way in the vast majority of cases, although the intensity of the increases/contractions, the duration of these periods and the precise moment in which they have occurred vary from one country to another. Since the crisis in 2008, however, trajectories have been much more disparate and difficult to predict. In many countries house prices continue to decline, but in a few they are rising and in others the direction is unclear and there are often increasing disparities between regions within countries.

In the Basque Autonomous Community, at the end of 2019 the GDP was close to the $2 \%$ and the level of employment is recovering at levels close to before the 2008 crisis, but the hiring conditions have worsened markedly, hampering the level of disposable income down and making difficult the access to housing and mobility. Only $8.3 \%$ of the new jobs are on an indefinite and full-time contract, and $40 \%$ of the employment created is temporary and part time. This involuntary part-time work and the proportion of temporary jobs have also expanded significantly in several European member states during the crisis. The employment rate has increased in almost all member states since the beginning 
of the recovery (around 2014), but in the euro area, the employment rate is still slightly lower than before the crisis, and achieving the Europe 2020 employment targets remains challenging for Spain and other member states.

Part of the 'Europe 2020' strategy for smart, sustainable, and inclusive growth sets out principles and ways to support fair and well-functioning labour markets and welfare systems. At the same time, in some regions there are several bottom-up local initiatives and policies for encouraging new social housing that favours internal immigration/mobility. Such grass-roots stimulus, activated in recent years in municipalities with low birth and immigration rates, are gaining some impact now that the worst years of economic crisis are over.

As land is a scarce resource and its use must be rational and sustainable, land use planning authorities should take these results into account, implementing more controlled land use policies to attract population to their village or town and also to manage rationally and sustainably the land of each municipality. Firstly, this could imply the use of more land for construction of public price housing and less for private price housing, in which prices follow real estate market tendency inducing extremely high housing prices. The construction of more public housing, with its controlled price associated, could be the way to the loss of population in a municipality and in its neighbours.

Secondly, the controlled land use policies should be defined at a regional context, not at a municipal one, since housing prices were and are similar in nearby municipalities. If prices are controlled at the regional level, residents will be attracted to the entire area and, therefore, to all municipalities. Future research directions might be the spatial econometric analysis of the three variables of the study in order to make a deeper analysis of the causal relationships between these and, ultimately, in order to design a more rational and sustainable land-use planning.

Author Contributions: Conceptualization, P.A.-E. and I.A.; methodology, P.A.-E. and I.A.; software, P.A.-E. and I.A.; validation, P.A.-E. and I.A.; formal analysis, P.A.-E. and I.A.; investigation, P.A.-E. and I.A.; resources, P.A.-E. and I.A.; data curation, P.A.-E. and I.A.; writing - original draft preparation, P.A.-E. and I.A.; writing-review and editing, P.A.-E. and I.A.; visualization, P.A.-E. and I.A.; supervision, P.A.-E. and I.A.. All authors have read and agreed to the published version of the manuscript.

Funding: This research was funded by the EUSKAL HERRIKO UNIBERTSITATEA/UNIVERSIDAD DEL PAÍS VASCO, $14 / 46$ research project.

Conflicts of Interest: The authors declare no conflict of interest.

\section{References}

1. Vasco, G. Departamento de Medioambiente, Planificación Territorial y Vivienda. In Revisión de las Directrices de Ordenación Territorial (DOT) de la CAPV; Departamento de Medioambiente, Planificación Territorial y Vivienda: Gobierno Vasco, España, 2018.

2. Instituto Nacional de Estadística (INE). Proyección de la Población de España: 2016-2066; Instituto Nacional de Estadística: Madrid, España, 2016.

3. Roback, J. Wage, rents, and the quality of life. J. Political Econ. 1982, 90, 1257-1278. [CrossRef]

4. Mueser, P.R.; Graves, P.E. Examining the role of economic opportunity and amenities in explaining population redistribution. J. Urban Econ. 1995, 37, 176-200. [CrossRef]

5. Thériault, M.; Le Berre, I.; Dubé, J.; Maulpoix, A.; Vandersmissen, M. The effects of land use planning on housing spread: A case study in the region of Brest, France. Land Use Policy 2020, 92, 1-19. [CrossRef]

6. Murphy, L. The politics of land supply and affordable housing: Auckland's Housing Accord and Special Housing Areas. Urban Stud. 2016, 53, 2530-2547. [CrossRef]

7. Dahl, M.S.; Sorenson, O. The migration of technical workers. J. Urban Econ. 2010, 67, 33-45. [CrossRef]

8. Buch, T.; Hamann, S.; Niebuhr, A. What makes cities attractive? The determinants of urban labour migration in Germany. Urban Stud. 2012, 51, 1960-1978. [CrossRef]

9. Peng, C.; Tsai, I. The long- and short-run influences of housing prices on migration. Cities 2019, 93, 253-262. [CrossRef]

10. Agnew, K.; Lyons, R.C. The impact of employment on housing prices: Detailed evidence from FDI in Ireland. Reg. Sci. Urban Econ. 2018, 70, 174-189. [CrossRef] 
11. Vermeulen, W.; van Ommeren, J. Does land use planning shape regional economies? A simultaneous analysis of housing supply, internal migration and local employment growth in the Netherlands. J. Hous. Econ. 2009, 18, 294-310. [CrossRef]

12. Plantinga, A.J.; Détang-Dessendre, C.; Hunt, G.L.; Piguet, V. Housing prices and inter-urban migration. Reg. Sci. Urban Econ. 2013, 43, 296-306. [CrossRef]

13. Saks, R.E. Job creation and housing construction: Constraints on metropolitan area employment growth. J. Urban Econ. 2008, 64, 178-195. [CrossRef]

14. Zabel, J.E. Migration, housing market, and labour market responses to employment shocks. J. Urban Econ. 2012, 72, 267-284. [CrossRef]

15. Jeanty, P.W.; Partridge, M.; Irwin, E. Estimation of a spatial simultaneous equation model of population migration and housing price dynamics. Reg. Sci. Urban Econ. 2010, 40, 343-352. [CrossRef]

16. Mitze, T.; Schmidt, T.D.; Rauhut, D.; Kangasharju, A. Ageing shocks and short-run regional labour market dynamics in a spatial panel VAR approach. Appl. Econ. 2018, 50, 870-890. [CrossRef]

17. Guo, Y.T.; Wang, H.W.; Nijkamp, P.; Xu, J.G. Space-time indicators in interdependent urban-environmental systems: A study on the Huai River Basin in China. Habitat Int. 2015, 45, 135-146. [CrossRef]

18. Agovino, M.; Ferrara, M.; Garofalo, A. An exploratory analysis on waste management in Italy: A focus on waste disposed in landfill. Land Use Policy 2016, 57, 669-681. [CrossRef]

19. Dou, Y.; Luo, X.; Dong, L.; Wu, C.; Liang, H.; Ren, J. An empirical study on transit-oriented low-carbon urban land use planning: Exploratory Spatial Data Analysis (ESDA) on Shanghai, China. Habitat Int. 2016, 53, 379-389. [CrossRef]

20. Poudyala, N.C.; Elkinsb, D.; Nibbelinkb, N.; Cordell, H.K.; Gyawali, B. An exploratory spatial analysis of projected hotspots of population growth, natural land loss, and climate change in the conterminous United States. Land Use Policy 2016, 51, 325-334. [CrossRef]

21. Eustat. Instituto Vasco de Estadística. In Panorama Demográfico 2014; Eustat: Vitoria, España, 2014.

22. López, F.A.; Matilla-García, M.; Mur, J.; Ruiz, M. Four tests of independence in spatiotemporal data. Pap. Reg. Sci. 2011, 90, 663-686. [CrossRef]

(C) 2020 by the authors. Licensee MDPI, Basel, Switzerland. This article is an open access article distributed under the terms and conditions of the Creative Commons Attribution (CC BY) license (http://creativecommons.org/licenses/by/4.0/). 